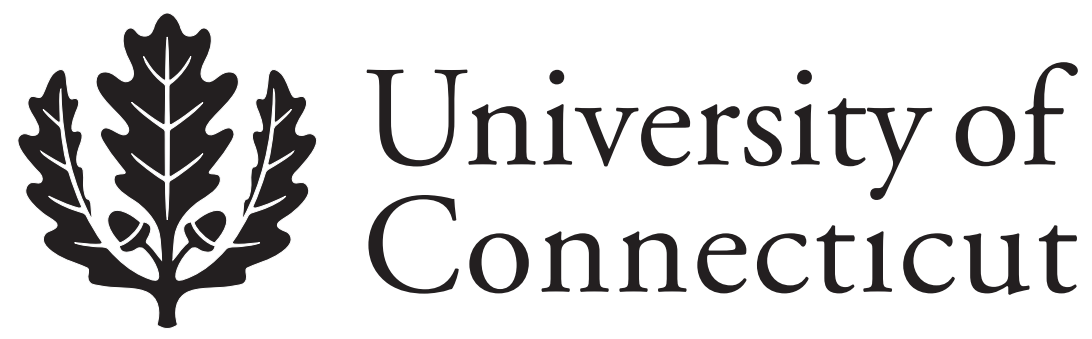

Department of Economics Working Paper Series

\title{
The Social versus Private Incentive to Sue
}

Thomas J. Miceli

University of Connecticut

Working Paper 2008-12

April 2008

341 Mansfield Road, Unit 1063

Storrs, CT 06269-1063

Phone: (860) 486-3022

Fax: (860) 486-4463

http://www.econ.uconn.edu/

This working paper is indexed on RePEc, http://repec.org/ 


\begin{abstract}
The private value of lawsuits is based on plaintiffs' expected recovery at trial compared to their filing costs, whereas the social value consists of the incentives suits create for injurers to invest in accident avoidance. Generally, there is no relationship between these two values: there may be either too many or too few suits from a social perspective. Thus, there is scope for corrective measures, although there is no simple policy. Extending the model to consider a negligence rule rather than strict liability, and to allow for pretrial settlements, leads to some modified conclusions but does not alter the basic insights.
\end{abstract}

Journal of Economic Literature Classification: K13, K40, K41

Keywords: Accidents, deterrence, lawsuits, litigation costs, social versus private value 


\section{The Social versus Private Incentive to Sue}

\section{Introduction}

The economic theory of tort law is based on the idea that the threat of liability provides potential injurers (those engaged in risky activities) with efficient incentives to take care to avoid accidents by forcing them to internalize the risk that their behavior creates. ${ }^{1}$ Unlike direct regulation or externality taxes, however, liability is a private remedy that can only be imposed if accident victims are willing to file suit to seek compensation. Because early models ignored the cost of litigation, however, they sidestepped the impact of legal costs both on the private incentive to sue, and on the social value of lawsuits as a means of internalizing harm.

Shavell (1982) was the first to explicitly compare the private and the social value

of lawsuits in a costly legal system. ${ }^{2}$ He pointed out that, while the private value of a suit depends solely on a plaintiff's comparison of the payment he or she expects to receive at trial with the cost of filing suit, the social value depends on the extent to which lawsuits induce the defendant to undertake socially desirable accident prevention. A key finding was that there is no necessary connection between these two values. That is, a suit may be privately valuable but not socially valuable, or the reverse may be true. As a result, in an unrestricted legal system, there may be either too much or too little litigation from a social perspective.

Section 2 of this article reviews this basic argument, focusing on the case of strict liability rule and assuming that all cases go to trial. Sections 3 and 4 then extend the model, first to consider a negligence rule, and then to allow settlements. Both extensions

\footnotetext{
${ }^{1}$ The first formal model of accidents was by Brown (1973). For comprehensive surveys of this literature, see Shavell (1987), Landes and Posner (1987), and Shavell (2004, Chapters 8-12).

${ }^{2}$ Also see Menell (1983), Kaplow (1986), Rose-Ackerman and Geistfeld (1987), and Shavell (1997, 1999).
} 
entail some modifications of the foregoing conclusions but do no nullify the basic insights. Section 5 considers several further extensions of the model, including the lawmaking function of trials, the impact of different cost allocation rules, and bilateral care accidents. Finally, Section 6 summarizes the conclusions.

\section{The Basic Model}

Consider a unilateral care accident model in which potential injurers can invest in care of $x$ dollars to reduce the probability of an accident, $p(x)$, where $p^{\prime}<0, p^{\prime \prime}>0$. In the event of an accident, the victim suffers a loss of $L$ dollars that is observable to the victim at the time of the accident but not to the injurer. The injurer, however, knows the distribution function of $L$ conditional on an accident, which is given by $F(L)$. The victim (plaintiff) can file suit at cost $k$, and the cost of a trial is $c_{p}$ to the plaintiff and $c_{d}$ to the defendant. In the basic model we assume that liability is strict and that all cases go to trial; later, we introduce a negligence rule and allow the possibility of settlement prior to trial.

Once an accident occurs, the plaintiff files suit if her expected gain at trial, $L-c_{p}$, exceeds the filing cost, or if $L \geq k+c_{p}$. This represents the condition for a suit to be privately valuable. The resulting probability of a suit, conditional on an accident, is 1$F\left(k+c_{p}\right)$.

To examine the social value of suits, we need to examine the incentives they create for defendants to take care to avoid accidents. In the event of an accident, the defendant's expected costs are given by

$$
A=\left(1-F\left(c_{p}+k\right)\right) E\left(L+c_{d} \mid L \geq k+c_{p}\right)
$$




$$
=\int_{k+c_{p}}^{\infty}\left(L+c_{d}\right) d F(L)
$$

Given $A$, the defendant chooses care to minimize his expected accident plus litigation costs:

$$
x+p(x) A
$$

The resulting first order condition

$$
1+p^{\prime}(x) A=0
$$

determines the injurer's optimal care, denoted $\hat{x}$. Totally differentiating (3) and using (1) implies that

$$
\frac{\partial \hat{x}}{\partial k}<0, \quad \frac{\partial \hat{x}}{\partial c_{p}}<0, \quad \frac{\partial \hat{x}}{\partial c_{d}}>0 .
$$

Thus, an increase in the plaintiff's filing or trial costs reduce the defendant's care by lowering the probability of a suit, conditional on an accident. Conversely, an increase in the defendant's trial costs increases his care by raising the expected cost of an accident.

The social desirability of lawsuits depends on how they affect overall social costs, including the plaintiff's damages plus total litigation costs. Expected social costs conditional on an accident are given by

$$
H=E(L)+\left(1-F\left(k+c_{p}\right)\right)\left(k+c_{p}+c_{d}\right)
$$

where $E(L)$ is the plaintiff's expected loss in the event of an accident. Comparing (5) and (1) shows that $A<H$; that is, defendants do not face the full social costs of an accident. This is true for two reasons: first, defendants ignore the damages suffered by victims who do not file suit, and second, they ignore the filing and trial costs of victims who do file. As a result, the threat of lawsuits underdeters injurers. 
Given this underdeterrence, we now ask whether lawsuits are socially desirable. First, we compute expected social costs, evaluated at the defendant's privately optimal care choice. The resulting cost expression is

$$
\hat{x}+p(\hat{x}) H .
$$

In contrast, if lawsuits are prohibited (or, equivalently, if the liability rule is switched to no liability), then injurers will take no care and no victims will file suit. Expected social costs in that case are

$$
p(0) E(L) .
$$

Lawsuits are socially valuable if (6) is less than (7), or, using (5), if

$$
p(\hat{x})\left[1-F\left(k+c_{p}\right)\right]\left(k+c_{p}+c_{d}\right)<p(0) E(L)-[\hat{x}+p(\hat{x}) E(L)] .
$$

The left-hand side of this condition represents the expected litigation costs of allowing lawsuits, while the right-hand side represents the deterrence benefits of lawsuits. Generally, this condition may or may not hold, implying that lawsuits may or may not be socially desirable. While the threat of suits is necessary to induce injurers to take care under a strict liability rule, the cost of using the legal system may outweigh the resulting deterrence benefits.

Further, there is no necessary relationship between the private and social value of lawsuits. As noted, the private value of a suit is solely determined by comparing an individual plaintiff's loss to her cost of bringing suit. Thus, when plaintiffs vary in their individual losses, some will find a suit privately valuable and others will not, regardless of the social value of suits. In contrast, the social value of lawsuits is based on aggregate costs across all plaintiffs since that is what determines the expected costs faced by injurers at the time they make their care choices. Thus, there will be too many suits when 
they are not socially valuable (i.e., when (8) does not hold), and there may be too many or too few when they are socially valuable (i.e., when (8) holds). ${ }^{3}$

\subsection{An Example}

A numerical example helps to illustrate the preceding points. Let the accident technology be given by $p(x)=.005 e^{-\theta x}$, where $\theta>0$ is a parameter reflecting the productivity of injurer care. Note that $p^{\prime}=-.005 \theta e^{-\theta x}<0$ and $p^{\prime \prime}=.005 \theta^{2} e^{-\theta x}>0$, as required, and $p(0)=.005$. Also let $k=\$ 50, c_{p}=c_{d}=\$ 300$, and suppose that $L$ is distributed uniformly on $[0, \$ 1,000]$. Thus, $E(L)=\$ 500$, and, from (1), $A=\$ 633.75$.

Now suppose that $\theta=1$. Then, from (3), the injurer's optimal care when lawsuits are allowed is $\hat{x}=\$ 1.153$. Substituting this value into $p(x)$ yields the risk of an accident: $p(\hat{x})=.00158 .^{4}$ The left-hand side of condition (8), the expected litigation costs of allowing lawsuits, therefore equals $\$ .668$, while the right-hand side, the expected deterrence benefits of lawsuits, equals \$.557. Since the left-hand side is larger, lawsuits are not socially valuable in this example.

To find a counterexample where lawsuits are socially valuable, let $\theta=2$, implying that injurer care is more productive than in the previous example. Proceeding as above, we find that the injurer's optimal care is now $\hat{x}=\$ .923$, while the resulting risk of an accident is $p(\hat{x})=.00079$. The left-hand side of (8) in this case is $\$ .334$, and the righthand side is $\$ 1.182$. Thus, lawsuits are now socially valuable. Finally, note that in both examples, the cost of a suit to plaintiffs is $k+c_{p}=\$ 350$, meaning that those plaintiffs with

\footnotetext{
${ }^{3}$ It is not possible to say in general whether there are too many or too few suits when (8) holds because, although not all victims file in this case, it is not necessarily true that adding more suits will be socially desirable. It depends on whether the extra cost is outweighed by the increased deterrence gains.

${ }^{4}$ It is easy to verify that $\hat{x}=-(1 / \theta) \ln [1 /(.005 A \theta)]$ and $p(\hat{x})=1 /(\theta A)$.
} 
$L \geq \$ 350$ file suit, while those with $L<\$ 350$ do not. Thus, in both examples, $65 \%$ of victims find suits privately valuable.

\subsection{Corrective Policies}

To what extent can the government enact corrective policies to achieve the socially optimal outcome? Observe first that if (8) does not hold, lawsuits are not socially desirable and therefore should be banned (or, equivalently, a rule of no liability should be instituted).

The problem is more complicated if (8) holds. Although suits are socially desirable in this case, and a fraction $1-F\left(k+c_{p}\right)$ of victims find them privately desirable, we have seen that injurers will take too little care because they ignore the losses of those victims who do not file suit, as well as the litigation cost of those victims who do. In principle, this can be remedied either by directly subsidizing suits so that more victims file, or by charging defendants damages in excess of the losses suffered by victims. ${ }^{5}$ Both of these policies, however, would have the undesirable effect of increasing the number of lawsuits, thereby raising litigation costs. Thus, overall social costs are not necessary reduced. A better approach would therefore be to impose a tax on defendants to be paid to the government rather than to plaintiffs, thus increasing incentives for care without incurring the higher litigation costs. ${ }^{6}$ In any event, enacting the optimal corrective policy, while possible in theory, would be difficult in practice and would require information that is not easily obtained by policymakers.

\footnotetext{
${ }^{5}$ A similar rationale underlies the economic theory of punitive damages (Shavell, 2004, pp. 243-247).

${ }^{6}$ The logical limit of this proposal would be to raise the cost imposed on defendants while simultaneously lowering the award to plaintiffs so as to improve incentives while reducing the number of suits. Such a policy is referred to as "decoupled liability" (Polinsky and Che, 1991). As a practical matter, however, the state is limited to policies that award plaintiffs no less than their actual losses, in which case the number of lawsuits cannot be reduced below $1-F\left(k+c_{p}\right)$.
} 


\section{The Model Under a Negligence Rule}

This section extends the model to the case of a negligence rule. Under a perfectly functioning negligence rule, ${ }^{7}$ an accident victim will file suit if $L \geq k+c_{p}$ and if the injurer was negligent. An injurer is judged negligent if he failed to comply with the due standard of care, $z$, in which case he is fully liable for the plaintiff's losses. Alternatively, the injurer can meet the due standard and avoid all liability. This is an important advantage of negligence over strict liability because it means that injurers can be induced to take care by the threat of a lawsuit rather than by the actual filing of suits. ${ }^{8}$

The injurer's problem under negligence is to choose $x$ to minimize

$$
\begin{array}{ll}
x, & \text { if } x \geq z \\
x+p(x) A, & \text { if } x<z,
\end{array}
$$

where $A$ is defined by (1). The solution to this problem depends on the due standard, $z$. An obvious candidate is first-best care, $x^{*}$, which is defined to be the level of care that minimizes expected accident costs in the absence of litigation costs, or $x+p(x) E(L)$. From (1) it should be apparent that $A$ may be larger or smaller than $E(L)$. It could be larger because it includes the defendant's trial costs in addition to liability, but it could be smaller because it does not include the losses suffered by victims who do not find it worthwhile to file suit. Thus, the level of care that minimizes the second line of (9), which we defined above to be $\hat{x}$, may be larger or smaller than $x^{*}=z$. If $\hat{x}>x^{*}$, the injurer will clearly comply with the due standard and, unlike the case under strict liability, the first-best outcome can be achieved. Specifically, the injurer will take the

\footnotetext{
${ }^{7}$ In reality, the negligence rule may function imperfectly for a number of reasons. For example, injurers may be uncertain about the due standard (Craswell and Calfee, 1986), or courts may apply the due standard with error (Png, 1986; Polinsky and Shavell, 1989; Hylton, 1990).

${ }^{8}$ An offsetting cost of negligence is that if a case does go to trial, it will likely be costlier compared to strict liability because, in addition to causation, the plaintiff must prove fault.
} 
efficient level of care and no victims will file suit, so no litigation costs are incurred. In this case, there is no possibility of an excessive private incentive to sue.

Alternatively, if $\hat{x}<x^{*}$, the injurer may or may not comply with the due care standard. If $\hat{x}$ is not too far below $x^{*}$ he will comply, and the first-best outcome will still be achieved. ${ }^{9}$ However, if $\hat{x}$ is significantly below $x *$ the injurer will find it cheaper not to comply but will instead choose $\hat{x}$ and be found negligent. In that case, the outcome is identical to that under strict liability, and the conclusions regarding the social versus private desirability of suit from that case carry over.

In the example from above, when $\theta=1, x^{*}=z=\$ .916$. Thus, since $\hat{x}=\$ 1.153$, the injurer will comply with the due standard, and the first-best outcome is achieved. (The same result occurs when $\theta=2$.)

\section{The Model when Settlement is Possible}

We now amend the above model to allow the settlement of lawsuits before trial (Shavell, 1999). ${ }^{10}$ For simplicity, we assume that settlement involves no costs to either party, though trials continue to $\cos t c_{p}$ and $c_{d}$ to plaintiffs and defendants, respectively. However, plaintiffs must incur the filing $\operatorname{cost} k$ whether they settle or go to trial.

Consider first the settlement-trial decision, given that an accident has occurred and a plaintiff has filed suit. Since the defendant cannot observe an individual plaintiff's loss, he must make a single settlement offer $S$ to minimize his expected costs (an amount to be derived shortly). A plaintiff of type $L$ will accept the offer if

$$
S \geq L-c_{p}
$$

\footnotetext{
${ }^{9}$ In particular, the injurer will comply if $x^{*} \leq \hat{x}+p(\hat{x}) A$.

${ }^{10} \mathrm{We}$ focus only on strict liability as the qualitative conclusions reached concerning a negligence rule in the model without settlement continue to apply.
} 
and refuse otherwise. Thus, plaintiffs with $L \leq S+c_{p}$ will settle, while those with $L>S+c_{p}$ will go to trial. ${ }^{11}$ The resulting probability of a trial, conditional on an accident occurring and a suit being filed, is $1-F\left(S+c_{p}\right)$.

In this case, the expected cost facing the defendant, conditional on an accident, is

$$
R(S)=F\left(S+c_{p}\right) S+\int_{S+c_{p}}^{\infty}\left(L+c_{d}\right) d F(L)
$$

The defendant chooses the settlement offer, $S$, to minimize this expression. The resulting first order condition (assuming an interior solution) is

$$
F\left(S+c_{p}\right)-\left(c_{p}+c_{d}\right) f\left(S+c_{p}\right)=0
$$

where $f(\bullet)$ is the density function associated with $F(\bullet)$. Let $S *$ represent the optimal settlement amount implied by (12).

We can now determine the private value of suit in this case. We will assume throughout that $S^{*}>k$, in which case a suit is privately valuable for all plaintiffs, regardless of their particular loss. Those with $L \leq S^{*}+c_{p}$ will therefore file and settle, yielding them a net return of $S^{*}-k$, while those with $L>S^{*}+c_{p}$ will file and go to trial, yielding them a net return of $L-c_{p}-k$ (which is positive given $\left.S^{*}>k\right) .{ }^{12}$ Compared to the model without settlement, more suits will be filed in this case because the possibility of settlement induces plaintiffs with $L<k+c_{p}$ to file, whereas they did not find it worthwhile to file in the above model.

\footnotetext{
${ }^{11}$ Note that the plaintiff's filing cost does not matter for the plaintiff's acceptance decision because it is sunk.

${ }^{12}$ A possible solution to the defendant's settlement problem is to offer $S=0$ (actually, any $S<k$ ) rather than $S^{*}$, in which case victims whose losses are less than the filing plus trial costs (i.e., those with $L<k+c_{p}$ ) would not rationally file suit. (Such cases are sometimes referred to as negative expected value cases.) The gain from this strategy is that the defendant avoids paying a positive settlement to these victims, but the cost is that he must incur trial costs with those victims who do file suit (those with $L \geq k+c_{p}$ ). The strategy of offering a zero settlement amount will be optimal if the gain exceeds the cost, which is more likely to be true the larger is the fraction of plaintiffs with $L<k+c_{p}$ in the population of plaintiffs. (See Bebchuk (1988) and Katz (1990).) In that case, the outcome is the same as when settlements are not possible.
} 
As above, the social value of suit depends on its ability to induce injurers to take care. The injurer's minimized cost when settlement is possible is the minimized value of (11), or $R\left(S^{*}\right)$. His optimal care choice therefore minimizes

$$
x+p(x) R\left(S^{*}\right)
$$

The resulting first order condition

$$
1+p^{\prime}(x) R\left(S^{*}\right)=0
$$

defines the optimal level of care $\tilde{x}$. It is interesting to compare the defendant's care in this case with the model in which settlement was not possible. Since the defendant always has the option in the current model to take all cases to trial by offering $S=0,{ }^{13}$ it must be the case that his costs are lower (or at least no higher) when he has the option to settle. Thus, $R\left(S^{*}\right) \leq A$, implying that $\tilde{x} \leq \hat{x}$. Thus, the possibility of settlement will tend to reduce the defendant's incentive to take care.

Consider next expected social costs when settlement is possible. Conditional on an accident having occurred, these costs are

$$
H_{S}=E(L)+k+\left(1-F\left(S^{*}+c_{p}\right)\right)\left(c_{p}+c_{d}\right) \text {. }
$$

Subtracting the injurer's minimized costs from this quantity yields

$$
H_{S}-R\left(S^{*}\right)=\int_{0}^{S^{*}+c_{p}}\left(L+k-S^{*}\right) d F(L)+\left[1-F\left(S^{*}+c_{p}\right)\right]\left(k+c_{p}\right) .
$$

In contrast to the case where settlement was not possible, this comparison is ambiguous. As before, social costs tend to be higher than private costs because the defendant ignores the plaintiff's filing and trial costs for those cases that go to trial. This is captured by the second term in (16). The first term, however, is ambiguous in sign, given our assumption that $S^{*}>k$. This reflects the fact that for cases that settle, the defendant overcompensates

\footnotetext{
${ }^{13}$ See footnote 12.
} 
those plaintiffs whose damages plus filing costs are less than the amount the defendant ends up paying them. Thus, although the defendant will not generally take the efficient level of care, we cannot determine whether he is over- or underdeterred (though underdeterrence seems to be the more plausible outcome). ${ }^{14}$

As before, the condition for lawsuits to be socially desirable in this case is

$$
\tilde{x}+p(\tilde{x}) H_{S}<p(0) E(L)
$$

which is ambiguous in sign based on the same factors discussed in connection with condition (8).

Continuing with the above example, we find that when settlement is possible, $S^{*}=\$ 300$ and $R\left(S^{*}\right)=\$ 620 .{ }^{15}$ Thus, $S^{*}>k$ and $R\left(S^{*}\right)<A(=\$ 633.75)$ as required. In the case where $\theta=1$, the injurer's optimal care choice is $\tilde{x}=\$ 1.131$, and the resulting risk of an accident is $p(\tilde{x})=.00161$. Thus, compared to the case where settlement was not allowed, the injurer takes less care $(\$ 1.131<\$ 1.153)$, and the probability of an accident is correspondingly higher (.00161>.00158). Finally, condition (17) holds in this case $(\$ 2.403<\$ 2.5)$, implying that suits are socially desirable. Recall that this was not true in the above example without settlements for the case of $\theta=1$. The opposite conclusion is obtained here because the possibility of settlement lowers the social cost of lawsuits more than it reduces incentives for care.

\section{Extensions}

This section discusses several extensions of the basic model.

\footnotetext{
${ }^{14}$ A comparison of social costs in the models with and without settlement similarly shows that the possibility of settlement may raise or lower social costs (i.e., $H_{S}-H$ is ambiguous in sign). On one hand, settlement causes some cases to be filed that otherwise would not have been, thereby raising filing costs, but on the other, settlement allows some trial costs to be saved.

${ }^{15}$ For the case of a uniform distribution for $L$, it turns out that $S^{*}=c_{d}$.
} 


\subsection{The Lawmaking Function of Trials}

An important social benefit of trials not accounted for in the model to this point is their lawmaking function. Trials potentially perform this function by allowing judges the opportunity to evaluate existing legal rules (precedents) and possibly replace them with more efficient rules (by which we mean rules that lower social costs by creating better incentives for injurers, and possibly victims, to invest in accident avoidance.) Settlements cannot perform this function because cases that settle never come before the court to be evaluated. Thus, to the extent that trials tend to promote the selection of more efficient rules over time, they are socially valuable. The key question, then, is whether or not this favorable selection is likely to occur.

Two possible mechanisms have been proposed. ${ }^{16}$ The first, originally advanced by Richard Posner, is that common law judges consciously (or unconsciously) promote efficiency by selecting more efficient rules. (See, for example, Posner (2003, p. 252).) This view, however, has not attracted much appeal because it relies on the motivation and incentives of judges, neither of which is well-understood. ${ }^{17}$ Another line of literature, beginning with Rubin (1977) and Priest (1977), has therefore suggested that the law may evolve toward efficiency without the help of judges. According to this "selective litigation" argument, inefficient laws will tend to be litigated more often than efficient laws because the former impose higher costs on victims. As a result, inefficient laws will come before the court to be evaluated more often. And as long as judges are neither completely bound by precedent nor systematically biased against efficiency, then

\footnotetext{
${ }^{16}$ For a more thorough discussion of this issue, see Cooter and Rubinfeld (1989, pp. 1091-1094).

${ }^{17}$ But see Posner (1995, Chapter 3) and Miceli and Cosgel (1994) for some initial efforts in that direction.
} 
inefficient laws will be overturned at a higher rate, and the law will gradually evolve toward efficiency.

More recent literature has attempted to incorporate the possible bias of judges into this selective litigation model. Extending a framework developed by Gennaioli and Schleifer (2007a,b), Miceli (2009) has shown that the direction of legal change depends on the relative strength of selective litigation and judicial bias. Specifically, the law will tend to evolve toward efficiency provided that the fraction of judges biased against the efficient rule is less than the conditional probability that a case reaching trial involves an inefficient law.

\subsection{Deterministic Damages}

Menell (1983) extended Shavell's (1982) original model by proposing a different formulation of the accident technology in which the victim's damages are a deterministic function of the injurer's care rather than being probabilistic. That is, damages occur with certainty but are decreasing in the injurer's care: $L=L(x)$, where $L^{\prime}<0$. Such a model is more descriptive of breach of contract or nuisance cases, as opposed to accidents. An implication of this alternative specification is that the injurer can determine, by his choice of care, whether or not the victim finds a suit profitable. Specifically, by choosing $x$ such that $L(x) \leq k+c_{p}$, he can forestall a suit. Using this model, Menell (1983) showed that the injurer's private choice of care coincides with the socially optimal choice. However, Kaplow (1986) and Rose-Ackerman and Geistfeld (1987) showed that it remains true that the victim's private incentive to sue is not necessarily optimal. Thus, a rule prohibiting suit might still be socially desirable. The details of these results are provided in the Appendix. 


\subsection{Alternative Cost Rules}

To this point, the analysis has concentrated on the American rule for cost allocation, under which plaintiffs and defendants pay their own legal costs. It has often been proposed, however, that switching to the English, or "loser-pays," rule would lower litigation costs by discouraging plaintiffs with weak or non-meritorious suits from filing. In the context of the model developed here, a non-meritorious suit would be one for which the victim's damages are not large enough to cover the filing plus trial costs. (Such suits are sometimes referred to as "negative expected value suits;" see, for example, Katz (1990) and Bebchuk (1988).)

Although a loser-pays rule would in fact encourage more of these suits to be filed, we have seen that this may or may not be socially desirable. Thus, as a general proposition, there is no reason to believe that the loser-pays rule will systematically improve the efficiency of the legal system (Shavell, 1997; Rose-Ackerman and Geistfeld, 1987). The same conclusion applies to contingent fees, under which plaintiffs only pay their legal fees if they receive a positive settlement amount or win at trial.

\subsection{Bilateral Care Accidents.}

Finally, we briefly consider how the conclusions from the unilateral care accident model extend to the case of bilateral care, where victims can also take care to avoid accidents. ${ }^{18}$ Formally, the probability of an accident in this case becomes $p(x, y)$, where victim care, $y$, reduces $p$ in the same manner as $x$. All other elements of the model remain the same.

Note first that the filing decision of victims is unaffected by this change, as victims still decide whether or not to sue based on a comparison of their expected gain at

\footnotetext{
${ }^{18}$ To my knowledge, this case has not been formally examined in the literature.
} 
trial to the filing cost. The real difference concerns the deterrent effect of suits. Suppose first that suits are allowed and liability is strict. Then, as before, the injurer will invest in a positive level of care because he expects to face lawsuits by some victims. (Specifically, he will choose $x$ to minimize (2) with $p(x)$ replaced by $p(x, y)$, taking $y$ as given.) As for victims, they too will choose a positive level of care; specifically, they will choose $y$ to minimize their expected uncompensated losses, which consist of their actual damages multiplied by the probability that they will not sue, plus their litigation costs multiplied by the probability that they will sue. (Remember that victims do not observe their actual damage until an accident occurs.) Thus, both injurers and victims take some care under strict liability, though neither takes the efficient level of care. ${ }^{19}$

Now suppose that suits are prohibited (or equivalently that the rule is no liability). In that case, injurers will take no care because they face no risk of a suit, but victims will invest in efficient care, given $x=0$. That is, they will choose $y$ to minimize their full expected costs (care plus expected damages). As in the unilateral care model, the desirability of suits depends on a comparison of social costs in the two cases. The main difference compared to the unilateral care model is that trials may or may not be beneficial in terms of deterrence, given the superior incentives for victim care under a rule prohibiting trial. This will tend to make suits less valuable as a means of promoting deterrence in this case, especially if victim care is very productive in reducing accident risk. Finally, as in the unilateral care case, a negligence rule may be able to achieve the first-best outcome in which both injurers and victims take efficient care, and no suits are filed.

${ }^{19}$ In fact, injurers and victims each face a share of social costs. 


\section{Conclusion}

The principal conclusions of this article can be summarized as follows. First, the private value of a lawsuit depends on the plaintiff's expected gain at trial compared to his or her cost of filing suit, while the social value depends on the incentives lawsuits create for injurers to undertake efficient care to prevent accidents. Second, the social and private value of lawsuits generally differ, but there is no necessary relationship between them - that is, there may be too many or too few suits. Third, while corrective policies could theoretically resolve this disconnect, there is no simple policy, and the requisite information, especially regarding the deterrent effects of lawsuits, is not easily obtained by policymakers. Fourth, a negligence rule potentially leads to the first best outcome (efficient injurer care and no suits) because victims will be discouraged from filing if the injurer meets the due standard. Several factors, however, make this outcome unlikely in practice. Fifth, the possibility of settlement generally reduces the deterrent effects of lawsuits by lowering the cost of accidents to injurers. However, settlement increases the private value of suits by inducing some plaintiffs to file who would not have done so in the absence of settlement (those at the low end of the damage distribution). Thus, the social value of suits may or may not increase compared to the model without settlement. Sixth, the lawmaking function of trials increases the social value of trials relative to a rule prohibiting trial. Finally, introducing victim care into the model will tend to make a rule prohibiting trial more desirable because of the incentives it creates for victims to take care. 


\section{Appendix}

In Menell's (1983) model, the injurer can forestall suit by choosing care such that $L(x) \leq k+c_{p}$ (assuming that when indifferent, the victim does not file). Obviously, the injurer will never choose more care than necessary. Thus, define $x_{n}$ by the equation

$$
L\left(x_{n}\right)=k+c_{p} \text {. }
$$

If the injurer instead chooses a level of care that results in a suit, he will choose $x$ to minimize $x+L(x)+c_{d}$. Let $x^{\prime}$ be the resulting care level. (Thus, $x^{\prime}$ solves the first order condition $1+L^{\prime}=0$.) The injurer will choose $x_{n}$, and forestall suit, if and only if

$$
x_{n} \leq x^{\prime}+L\left(x^{\prime}\right)+c_{d}
$$

Now consider social costs. If the injurer chooses $x_{n}$, social costs are $x_{n}+L\left(x_{n}\right)$, whereas if he chooses $x^{\prime}$, social costs are $x^{\prime}+L\left(x^{\prime}\right)+k+c_{p}+c_{d}$. It is therefore socially optimal for the injurer to choose $x_{n}$ if and only if

$$
x_{n}+L\left(x_{n}\right) \leq x^{\prime}+L\left(x^{\prime}\right)+k+c_{p}+c_{d}
$$

Substituting for $L\left(x_{n}\right)$ from (A1) and cancelling terms immediately transforms (A3) into (A2). Thus, the social and private conditions are identical.

The preceding has assumed that suits are always allowed, but now consider the possible optimality of a rule prohibiting suit. Suppose first that suits occur according to the above analysis (that is, the inequality in (A2) is reversed.) If in this case suits were prohibited, the injurer would take zero care, yielding social costs of $L(0)$. This is preferred to the outcome with suits if and only if

$$
L(0)<x^{\prime}+L\left(x^{\prime}\right)+k+c_{p}+c_{d}
$$

Since this condition may or may not hold, a rule prohibiting suits may be optimal.

Alternatively, suppose that (A2) holds, so the defendant forestalls suits (though suits are allowed). It is socially desirable for the state to prohibit suits in this case if

$$
L(0)<x_{n}+L\left(x_{n}\right) .
$$

Again, this condition may or may not hold. (Obviously, it will not hold for $x_{n} \leq x^{\prime}$ since, by definition, $x+L(x)$ is decreasing in $x$ up to $x^{\prime}$. Thus, it can only hold for $x_{n}$ substantially greater than $x^{\prime}$. But note that this is not ruled out by (A2).) If (A5) holds, then a rule prohibiting suit would be desirable even though the defendant forestalls suits by his choice of care. (While the prohibition of suits does not save litigation costs in this case, it reduces the defendant's choice of care from $x_{n}$ to zero which, if (A5) holds, lowers social costs.) 


\section{References}

Bebchuk, Lucian (1984), 'Litigation and Settlement Under Imperfect Information', 15 Rand Journal of Economics, 404-415. (1988), 'Suing Solely to Extract a Settlement Offer', 17 Journal of Legal Studies, 437-450.

Brown, John (1973), 'Toward an Economic Theory of Liability', 2 Journal of Legal Studies, 323-349.

Cooter, Robert, and Daniel Rubinfeld (1989), 'An Economic Analysis of Legal Disputes and Their Resolution', 27, 1067-1097.

Craswell, Richard, and John Calfee (1986), 'Deterrence and Uncertain Legal Standards', 2, 279-303.

Gennaioli, Nicola, and Andrei Schleifer (2007a), 'The Evolution of the Common Law', 115, 43-68. (2007b), 'Overruling and the Instability of Law', 35 Journal of Comparative Economics, 309-328.

Hylton, Keith (1990), 'Costly Litigation and Legal Error Under Negligence', 6 Journal of Law, Economics, and Organization, 433-452.

Kaplow, Louis (1986), 'Private versus Social Costs in Bringing Suits', 15 Journal of Legal Studies, 371-385.

Katz, Avery (1990), 'The Effect of Frivolous Litigation on the Settlement of Legal Disputes', 10 International Review of Law and Economics, 3-27.

Landes, William, and Richard Posner (1987), The Economic Structure of Tort Law, Cambridge, MA: Harvard Univ. Press.

Menell, Peter (1983), 'A Note on Private versus Social Incentives to Sue in a Costly Legal System’, 12 Journal of Legal Studies, 41-52.

Miceli, Thomas (2009), 'Legal Change: Selective Litigation, Judicial Bias, and Precedent', Journal of Legal Studies, forthcoming.

Miceli, Thomas, and Metin Cosgel (1994), 'Reputation and Judicial Decision-making', 23 Journal of Economic Behavior and Organization, 31-51.

Png, I.P.L. (1986), 'Optimal Subsidies and Damages in the Presence of Legal Error', 6 International Review of Law and Economics, 101-105. 
Polinsky, A. Mitchell, and Y.K. Che (1991), 'Decoupling Liability: Optimal Incentives for Care and Litigation', 22 Rand Journal of Economics, 562-570.

Polinsky, A. Mitchell, and Steven Shavell (1989), 'Legal Error, Litigation, and the Incentive to Obey the Law', 5 Journal of Law, Economics, and Organization, 99108.

Posner, Richard (2003), Economic Analysis of Law, $6^{\text {th }}$ Edition, New York: Aspen Law \& Business. (1995), Overcoming Law, Cambridge, MA: Harvard Univ. Press.

Priest, George (1977), 'The Common Law Process and the Selection of Efficient Rules', 6, 65-82.

Rose-Ackerman, Susan, and Mark Geistfeld (1987), 'The Divergence between Social and Private Incentives to Sue: A Comment on Shavell, Menell, and Kaplow', 16 Journal of Legal Studies, 483-491.

Rubin, Paul (1977), 'Why is the Common Law Efficient?' 3 Journal of Legal Studies, 51-63.

Shavell, Steven (2004), Foundations of Economic Analysis of Law, Cambridge, MA: Belknap Press.

(1999), The Level of Litigation: Private versus Social Optimality of Suit and of Settlement', 19 International Review of Law and Economics, 99-115.

(1997), 'The Fundamental Divergence between the Private and the Social Motive to Use the Legal System', 26 Journal of Legal Studies, 575-612.

(1987), Economic Analysis of Accident Law, Cambridge, MA: Harvard Univ. Press.

(1982), 'The Social versus the Private Incentive to Bring Suit in a Costly Legal System', 11 Journal of Legal Studies, 333-339. 